\title{
Low-temperature irradiation effects in lithium orthosilicates
}

\author{
E. Feldbach ${ }^{\text {a }}$, A. Kotlov ${ }^{\text {a }}$, I. Kudryavtseva ${ }^{\text {a }}$, P. Liblik ${ }^{\text {a }}$, A. Lushchik ${ }^{\text {a,*, }}$ \\ A. Maaroos ${ }^{\text {a }}$, I. Martinson ${ }^{\text {b }, ~ V . ~ N a g i r n y i ~}{ }^{\text {a }}$, E. Vasil'chenko ${ }^{\text {a }}$ \\ a Institute of Physics, University of Tartu, Riia Street 142, Tartu 51014, Estonia \\ b Department of Physics, Lund University, Professorsgatan 1, S-22100 Lund, Sweden
}

Available online 12 June 2006

\begin{abstract}
The emission spectra of lithium orthosilicates $\left(\mathrm{Li}_{4} \mathrm{SiO}_{4}\right)$ ceramics have been measured in the range of $1.8-5.8 \mathrm{eV}$ under irradiation by 6-30 eV photons or 1-30 keV electrons at 6-300 K. The tunnel recombination phosphorescence, as well as luminescence, stimulated by $1.5-2.5 \mathrm{eV}$ photons has been detected in the sample preliminarily irradiated at 6 or $80 \mathrm{~K}$. The main peaks of thermally stimulated luminescence (TSL) in the irradiated ceramics have been observed at 72, 118 and $265 \mathrm{~K}$. The creation spectra of the $118 \mathrm{~K}$ TSL peak, as well as the excitation spectrum of photostimulated luminescence (PSL) span the region of the intrinsic absorption of a lithium orthosilicate $(9-30 \mathrm{eV})$. The intensity of PSL and the TSL peaks in $\mathrm{Li}_{4} \mathrm{SiO}_{4}$ ceramics prepared in hydrogen/argon atmosphere is several times lower than that in the mainly investigated $\mathrm{Li}_{4} \mathrm{SiO}_{4}$ ceramics prepared in the atmosphere of dry argon. The optical characteristics of $\mathrm{Li}_{4} \mathrm{SiO}_{4}$ are compared with the ones known for $\mathrm{Li}_{2} \mathrm{O}$ and $\mathrm{SiO}_{2}$. Low-temperature luminescent methods are promising for the investigation of electron-hole processes and radiation defects serving as the traps for tritium released in $\mathrm{D}-\mathrm{T}$ fusion reactor blanket systems.
\end{abstract}

(C) 2006 Elsevier B.V. All rights reserved.

PACS: $61.82 . \mathrm{Ms} ; 78.55 .-\mathrm{m} ; 78.60 .-\mathrm{Kn}$

Keywords: Luminescence; Radiation defect; $\mathrm{Li}_{4} \mathrm{SiO}_{4}$

\section{Introduction}

Lithium orthosilicate $\left(\mathrm{Li}_{4} \mathrm{SiO}_{4}\right)$ is one of the most attractive candidates for solid tritium breeding materials in $\mathrm{D}-\mathrm{T}$ fusion reactors $[1-4]$ and as a lithium ion conductor [5]. $\mathrm{A} \mathrm{Li}_{4} \mathrm{SiO}_{4}$ complex compound consists of $\mathrm{SiO}_{4}$ tetrahedrons and small-radius $\mathrm{Li}$ atoms bonded to the oxygen atoms. The results of long-standing investigations of the physical processes in $\alpha-\mathrm{SiO}_{2}$ crystals and other silicates [6-8], as well as in $\mathrm{Li}_{2} \mathrm{O}$ single crystals and ceramics [912], will be useful for the study of lithium orthosilicates. The main applications of $\mathrm{Li}_{4} \mathrm{SiO}_{4}$ ceramics are expected at temperatures close to the melting point $\left(1230^{\circ} \mathrm{C}\right)$ of the material. Low-temperature optical and radiation processes in $\mathrm{Li}_{4} \mathrm{SiO}_{4}$ have obviously been insufficiently studied.

\footnotetext{
${ }^{*}$ Corresponding author. Tel.: +3727 383026; fax: +3727383033 . E-mail address: luch@fi.tartu.ee (A. Lushchik).
}

At the same time, the low-temperature investigations (2$80 \mathrm{~K})$ of excitonic, electron-hole $(\mathrm{e}-\mathrm{h})$ and interstitialvacancy $(\mathrm{i}-\mathrm{v})$ processes in simple lithium-containing materials (e.g. LiF) had a profound impact on the interpretation of the phenomena at room temperature and significantly higher temperatures (see, e.g. $[13,14])$.

The aim of the present study is to investigate the lowtemperature $(5-300 \mathrm{~K})$ processes in lithium orthosilicate ceramics by means of up-to-date methods of vacuum ultraviolet (VUV) spectroscopy and highly sensitive methods of thermally or photostimulated luminescence (TSL and PSL).

\section{Experimental}

Ceramic samples of a $\mathrm{Li}_{4} \mathrm{SiO}_{4}$ complex oxide compound were prepared at the Institute of Physics, Tartu University, by a 4-h firing of pressed pellets of highly pure $\mathrm{Li}_{4} \mathrm{SiO}_{4}$ $(99.9 \%$, Alfa-Aesar Co.) in the atmosphere of dry argon 
or $\mathrm{Ar} / \mathrm{H}_{2}(10 \%)$ mixture at $1000{ }^{\circ} \mathrm{C}$, and a subsequent rapid cooling of the sample in an argon stream. Further, these two types of samples will bear the names $\mathrm{Li}_{4} \mathrm{SiO}_{4}-1$ and $\mathrm{Li}_{4} \mathrm{SiO}_{4}-2$, respectively. To prepare a $\mathrm{Li}_{4} \mathrm{SiO}_{4}-3$ sample, about $1 \mathrm{~mol} \%$ of $\mathrm{GeO}_{2}$ was added to $\mathrm{Li}_{4} \mathrm{SiO}_{4}$ before its final firing in the argon atmosphere.

Cathodoluminescence (CL) was simultaneously detected by a two-channel system: (1) in the region of $4-12 \mathrm{eV}$, a double vacuum-grating monochromator and a photomultiplier Hamamatsu R6838; and (2) in the region of 1.5$6.0 \mathrm{eV}$, a double prism monochromator and a Hamamatsu H6240 photon-counting head. The CL spectra were measured at $6-300 \mathrm{~K}$ at the excitation by an electron gun (1$30 \mathrm{keV}, 10-100 \mathrm{nA}$, spot size $\sim 0.5 \mathrm{~mm}^{2}$ ). After the electron irradiation of a sample, it was possible to register the TSL (for different emissions selected through a double prism monochromator) by heating the irradiated sample with a constant rate of $\beta=10 \mathrm{~K} \mathrm{~min}^{-1}$.

The PSL method for the study of $\mathrm{e}-\mathrm{h}$ and $\mathrm{i}-\mathrm{v}$ processes was earlier elaborated in Tartu and then applied also to synchrotron experiments with alkali halides [15], simple and complex oxides (e.g. MgO:Be [16]) and metal tungstates [17] at beamline BL52 at the MAX-Lab, Lund. Our preliminary experiments showed that the additional stimulation by visible or IR light of the $\mathrm{Li}_{4} \mathrm{SiO}_{4}$ ceramics, preliminarily irradiated at 8 or $80 \mathrm{~K}$, causes the radiative recombination of carriers, i.e. the appearance of PSL. The spectroscopic experiments with synchrotron radiation were mainly performed at the SUPERLUMI station of HASYLAB at DESY, Hamburg (see [18] for details). The excitation spectra of various emissions (selected by a monochromator) were normalized to equal quantum intensities of incident synchrotron radiation.

\section{Experimental results and discussion}

Inset of Fig. 1 shows the emission spectra measured at $10 \mathrm{~K}$ at the excitation of $\mathrm{Li}_{4} \mathrm{SiO}_{4}-1$ by 11 or $23 \mathrm{eV}$ photons, which form separated electrons and holes. The spectra consist of two main broad bands with the maxima at 2.9 and $3.8 \mathrm{eV}$ and two weak emissions at $\sim 2 \mathrm{eV}$ and $\geqslant 4.7 \mathrm{eV}$. The emissions of 2.9 and $\sim 2 \mathrm{eV}$ dominate in case of the sample excitation by $h v_{\mathrm{exc}}=6.5 \mathrm{eV}$. Two main emission bands at $\sim 2.9$ and $\sim 3.8 \mathrm{eV}$ are detected in the spectrum of $\mathrm{CL}$ of $\mathrm{Li}_{4} \mathrm{SiO}_{4}-1$ at $6 \mathrm{~K}$. At room temperature, the 3.8-eV emission undergoes a strong thermal quenching. The emission band peaked at $3.8 \mathrm{eV}$ is also drastically depressed in the $\mathrm{CL}$ spectrum measured at $6 \mathrm{~K}$ for a $\mathrm{Li}_{4} \mathrm{SiO}_{4}-2$ sample prepared in a reducing $\mathrm{Ar} / \mathrm{H}_{2}$ atmosphere. We failed to detect any emission in the region of 6-10 eV for the $\mathrm{Li}_{4} \mathrm{SiO}_{4}$ samples.

It is known that the emission of self-trapped excitons (STEs) has a maximum at $2.8 \mathrm{eV}$ at the excitation of an $\alpha-\mathrm{SiO}_{2}$ crystal in the regime of two-photon absorption (ArF eximer laser, $2 \times 6.4 \mathrm{eV}$ ) at $8 \mathrm{~K}$ [19], while the absorption maximum of a neutral oxygen vacancy (an $\mathrm{F}$ center) is located at $7 \mathrm{eV}$, i.e. in the region of the efficient excitation

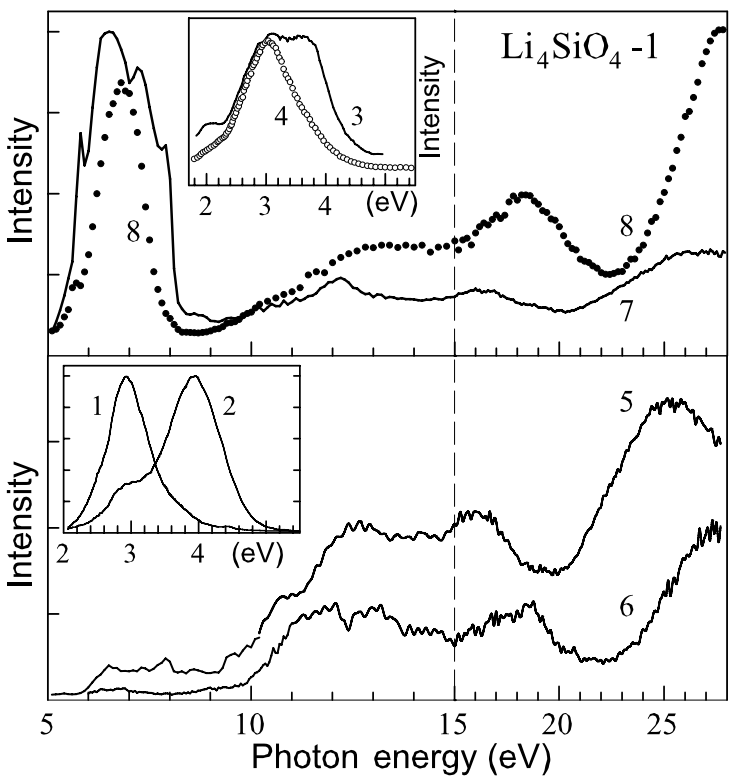

Fig. 1. The emission spectra (1-4) and the excitation spectra of several emissions (5-8) measured for a $\mathrm{Li}_{4} \mathrm{SiO}_{4}-1$ sample at $10 \mathrm{~K}(1-3,5-7)$ and $295 \mathrm{~K}(4,8)$. The emission spectra are measured at the excitation by $6.5 \mathrm{eV}$ (1), $23(2)$ and $11 \mathrm{eV}(3,4)$, the excitation spectra are measured for $3.9 \mathrm{eV}$ (5), $5.4(6), 2.8$ (7) and $2.3 \mathrm{eV}(8)$ emissions.

of 5-eV emission [20]. In $\mathrm{Li}_{2} \mathrm{O}$ single crystals at $9 \mathrm{~K}$, two emission bands at $3.7 \mathrm{eV}\left(h v_{\mathrm{exc}}=6.8 \mathrm{eV}\right)$ and $4.75 \mathrm{eV}$ $\left(h v_{\mathrm{exc}}=7.7 \mathrm{eV}\right)$ [11], as well as the $4-\mathrm{eV}$ absorption band related to the so-called $\mathrm{F}^{+}$centers (an electron in the field of an anion vacancy) $[9,10]$ have been revealed. One might expect the analogous emissions of STEs, $\mathrm{F}$ and $\mathrm{F}^{+}$centers in $\mathrm{Li}_{4} \mathrm{SiO}_{4}$ ceramics as well.

Fig. 1 also presents the excitation spectra of several emissions measured for $\mathrm{Li}_{4} \mathrm{SiO}_{4}-1$ using synchrotron radiation of $5-28 \mathrm{eV}$ at 10 and $295 \mathrm{~K}$. The efficiency of the 2.9- and 2.3-eV emissions is especially high at $h v_{\mathrm{exc}}=6-8$ $\mathrm{eV}$. A sharp increase of the efficiency of the 3.9- and 5.4-eV emissions occurs at $h v_{\mathrm{exc}}=9.5 \mathrm{eV}$; the efficiency value remains high at $12-17 \mathrm{eV}$ and it approximately doubles at $26-28 \mathrm{eV}$. Similar to other wide-gap dielectrics (including $\mathrm{Al}_{2} \mathrm{O}_{3}$ [21], $\mathrm{Y}_{2} \mathrm{SiO}_{4}$ and $\mathrm{Zn}_{2} \mathrm{SiO}_{4}$ [22], $\mathrm{SiO}_{2}$ and aluminosilicates [8]), the phenomenon of the multiplication of electronic excitations (MEE) takes place in $\mathrm{Li}_{4} \mathrm{SiO}_{4}$ at $h v_{\text {exc }} \geqslant 23 \mathrm{eV}$. Under MEE conditions, an absorbed exciting photon causes the creation of more than one electronic excitation.

An intense and prolonged phosphorescence was detected in $\mathrm{Li}_{4} \mathrm{SiO}_{4}-1$ after the end of a short irradiation by an electron beam $(20 \mathrm{keV}, 10 \mathrm{nA}, 2 \mathrm{~min})$. After the initial stage, comparable to the duration of irradiation, the phosphorescence exhibits distinctive features of tunnel recombination luminescence and its intensity drops with time by a power law $I \sim t^{-\alpha}$, where $\alpha=0.696$. The band with the maximum at $2.8 \mathrm{eV}$ dominates in the afterglow spectrum.

Fig. 2 shows the curve of low-temperature TSL for a $\mathrm{Li}_{4} \mathrm{SiO}_{4}-1$ sample irradiated by $20 \mathrm{keV}$ electrons at $6 \mathrm{~K}$. 


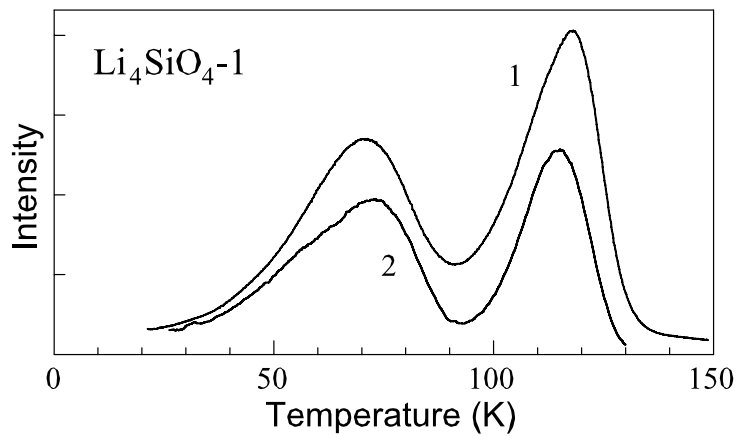

Fig. 2. The TSL curves measured for $2.9 \mathrm{eV}$ in $\mathrm{Li}_{4} \mathrm{SiO}_{4}-1$ irradiated by $20 \mathrm{keV}$ electrons at $6 \mathrm{~K}(1)$ or $11 \mathrm{eV}$ photons at $10 \mathrm{~K}(2) . \beta=10 \mathrm{~K} \mathrm{~min}^{-1}$.

Two main TSL peaks at 72 (a nonelemental one) and $118 \mathrm{~K}$ have been detected for $(2.9 \pm 0.1) \mathrm{eV}$ emission at the heating rate of $\beta=10 \mathrm{~K} \mathrm{~min}^{-1}$. After several additional preheating of the irradiated sample up to 20,50 and $60 \mathrm{~K}$, it was possible to separate a weak TSL at $35-40 \mathrm{~K}$ against the background of the tunnel recombination phosphorescence. An additional study of this weak TSL peak is planned. Integral TSL has been detected also after selective irradiation of the sample by synchrotron radiation of 11,14 and $19 \mathrm{eV}$. In all the cases, the TSL curves contained the same peaks as those after electron irradiation (see Fig. 2). Similar to $\mathrm{LiF}$ and $\mathrm{SiO}_{2}$ materials with simpler structure (see, e.g. $[13,14]$ and $[6,7]$, respectively), the TSL in the region of $80-150 \mathrm{~K}$, induced by electron or VUV irradiation, is caused mainly by $\mathrm{e}-\mathrm{h}$ processes.

Fig. 3 shows the TSL curve measured after the irradiation of $\mathrm{Li}_{4} \mathrm{SiO}_{4}-1$ by $1.5-\mathrm{keV}$ electrons at $6 \mathrm{~K}$. Such electrons are not able to create any defects due to the impact mechanisms in lithium orthosicilates. Nevertheless, the peaks at 72 and $118 \mathrm{~K}$ are detected for the $2.8-\mathrm{eV}$ emission. Weak TSL peaks at 205 and $265 \mathrm{~K}$ can be registered for the $3.8-\mathrm{eV}$ emission during heating of the irradiated sample from 160 to $390 \mathrm{~K}$. The intensity of the $265 \mathrm{~K}$ peak is about 60 times as low as that of the TSL peak at $118 \mathrm{~K}$. Fig. 3 also shows the TSL curve measured for the $2.8-\mathrm{eV}$ emission

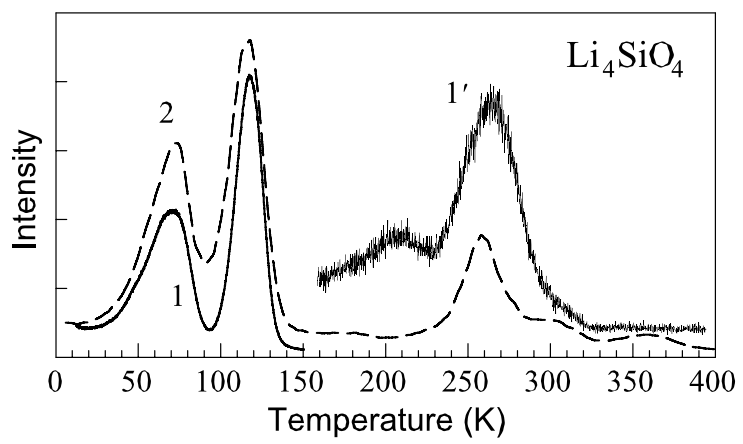

Fig. 3. The TSL curves measured for $\mathrm{Li}_{4} \mathrm{SiO}_{4}-1\left(1,1^{\prime}\right)$ and $\mathrm{Li}_{4} \mathrm{SiO}_{4}-3$ (2) samples irradiated by $1.50 \mathrm{keV}\left(1,1^{\prime}\right)$ and $20 \mathrm{keV}$ electrons (2) at $6 \mathrm{~K}$. The TSL was measured for $2.8(1,2)$ and $3.8 \mathrm{eV}\left(1^{\prime}\right)$ emissions, $\beta$ $=10 \mathrm{~K} \mathrm{~min}^{-1}$. after the $20-\mathrm{keV}$ electron irradiation of a $\mathrm{Li}_{4} \mathrm{SiO}_{4}-3$ sample containing $\mathrm{GeO}_{2}$. Intense TSL peaks at 72,118 and $265 \mathrm{~K}$ and weak peaks at 180,300 and $360 \mathrm{~K}$ were detected in this sample.

Fig. 4 demonstrates the TSL curve for a $\mathrm{Li}_{4} \mathrm{SiO}_{4}-1$ sample irradiated by $20-\mathrm{keV}$ electrons at $8 \mathrm{~K}$ and stored for $48 \mathrm{~h}$ under vacuum conditions at $295 \mathrm{~K}$. Integral TSL of this irradiated sample was measured with the heating rate $\beta=2.86 \mathrm{~K} \mathrm{~s}^{-1}$ in the atmosphere of flowing nitrogen (System 310 TLD Reader). High-temperature TSL peaks at $430,470,545$ and $670 \mathrm{~K}$ were detected.

In neutron-irradiated $\mathrm{Li}_{4} \mathrm{SiO}_{4}$ ceramics, the peaks of tritium release rate were observed in the region of $450-750 \mathrm{~K}$ [2]. These peaks were ascribed to the annealing of the charged defects that served as the traps for highly mobile tritium. An example of such traps is $\mathrm{F}^{+}$centers, which have been thoroughly studied in $\mathrm{Li}_{2} \mathrm{O}$ crystals $[9,10]$. The spectrum of radiation-induced optical absorption consists of $\mathrm{F}^{+}$-band peaked at $\sim 4 \mathrm{eV}$ and a broad band at $1.7_{-}$ $2.3 \mathrm{eV}$. We made an attempt to complement a relatively low-sensitive absorption method of the investigation of the irradiated samples of $\mathrm{Li}_{4} \mathrm{SiO}_{4}$ by highly sensitive luminescent methods. The additional stimulation of $\mathrm{Li}_{4} \mathrm{SiO}_{4}-1$ $\mathrm{X}$-irradiated at $80 \mathrm{~K}$ by $1.6-2.4 \mathrm{eV}$ photons (selected through a double prism monochromator) leads to the appearance of PSL in the region of $2.7-3.2 \mathrm{eV}$ (selected through an optical filter).

The inset in Fig. 5 shows the integral TSL curve measured with $\beta=10 \mathrm{~K} \mathrm{~min}^{-1}$ for a $\mathrm{Li}_{4} \mathrm{SiO}_{4}-1$ sample irradiated by $10.5-\mathrm{eV}$ photons at $80 \mathrm{~K}$. The $118 \mathrm{~K}$ peak (an activation energy of $180 \mathrm{meV}$ ) correlates well with the annealing of the PSL intensity measured in the regime of pulse heating: the stimulation by $1.8 \mathrm{-eV}$ photons at $80 \mathrm{~K}$ after the preheating of the sample up to a certain temperature $T_{i}=90-140 \mathrm{~K}$. After the photostimulation at $80 \mathrm{~K}$, the intense secondary phosphorescence connected with a repeat localization and release of carriers from shallow traps (TSL at 72-75 K) was detected in $\mathrm{Li}_{4} \mathrm{SiO}_{4}-1$.

Fig. 5 demonstrates the creation spectrum of PSL of $\sim 2.9 \mathrm{eV}$ measured for $\mathrm{Li}_{4} \mathrm{SiO}_{4}-1$ irradiated by equal quantum doses of $7.5-28-\mathrm{eV}$ photons at $10 \mathrm{~K}$. When an

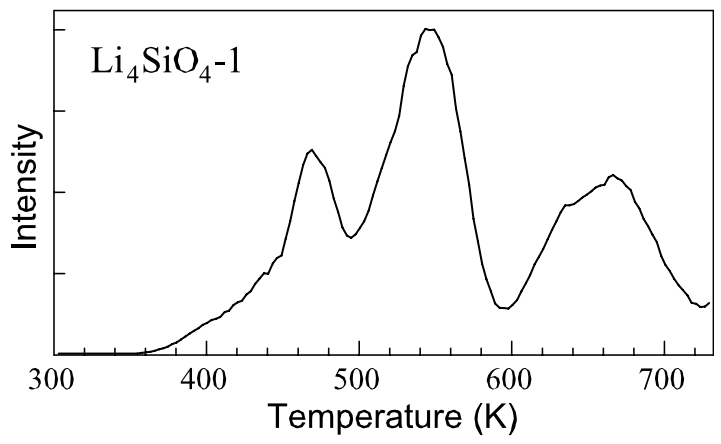

Fig. 4. The integral TSL measured for a $\mathrm{Li}_{4} \mathrm{SiO}_{4}-1$ sample irradiated by $20 \mathrm{keV}$ electrons at $8 \mathrm{~K}$ and stored for $48 \mathrm{~h}$ under vacuum conditions at $295 \mathrm{~K} . \beta=2.86 \mathrm{~K} \mathrm{~s}^{-1}$. 


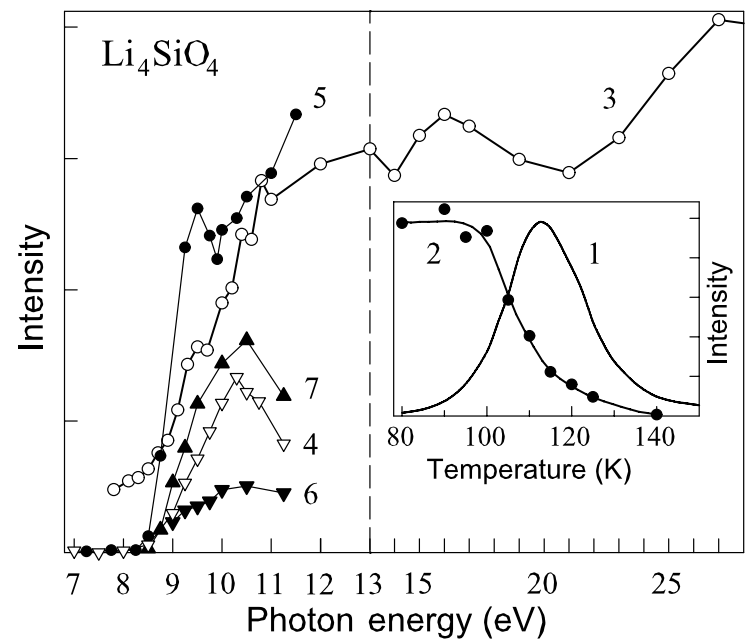

Fig. 5. The integral TSL (1) and pulse annealing of the PSL (2.7-3.2 eV), stimulated by $1.8 \mathrm{eV}$ photons (2), measured for a $\mathrm{Li}_{4} \mathrm{SiO}_{4}-1$ sample irradiated by $10.5 \mathrm{eV}$ photons at $80 \mathrm{~K}$. The creation spectra of the PSL measured under VUV-irradiation of $\mathrm{Li}_{4} \mathrm{SiO}_{4}-1$ at $10 \mathrm{~K}$ (3) and $80 \mathrm{~K}$ (4). The spectra of the $118 \mathrm{~K}$ TSL peak creation by VUV radiation at $80 \mathrm{~K}$ in $\mathrm{Li}_{4} \mathrm{SiO}_{4}-1$ (5), $\mathrm{Li}_{4} \mathrm{SiO}_{4}-2$ (6) and $\mathrm{Li}_{4} \mathrm{SiO}_{4}-2$ preliminarily fired at $773 \mathrm{~K}$ (7).

additional stimulation of the VUV-irradiated sample is started, the PSL intensity slightly increases, reaches the maximum value, and then decreases. The rising stage is caused by a tunnel recharging of defects at $10 \mathrm{~K}$ that provides the increase of the number of centers responsible for PSL. The light sum detected during $15 \mathrm{~s}$ (since the maximum value was reached) was taken as a measure of the PSL efficiency. Before measuring the next point in the creation spectrum, a total deexcitation of the sample (the intensity of PSL approaches zero) was carried out by means of an intense stimulation by $1.8 \mathrm{-eV}$ photons. The efficiency of PSL sharply increases in the region of fundamental absorption at $h v_{\mathrm{exc}} \geqslant 9 \mathrm{eV}$ as well as in the multiplication region of $h v_{\mathrm{exc}}>23 \mathrm{eV}$ (compare with Fig. 1). The intensity of PSL, measured in $\mathrm{Li}_{4} \mathrm{SiO}_{4}-15 \mathrm{~min}$ after the $10.5-\mathrm{eV}$ photon irradiation at $80 \mathrm{~K}$ is stopped, sharply increases with the rise of the irradiation dose during $15 \mathrm{~min}$ and then linearly increases during $2 \mathrm{~h}$.

Fig. 5 shows the creation spectra of PSL and the $118 \mathrm{~K}$ TSL peak by equal quantum doses of VUV radiation (7.0 $11 \mathrm{eV}$ ) at $80 \mathrm{~K}$ in a $\mathrm{Li}_{4} \mathrm{SiO}_{4}-1$ sample. The efficiency of PSL is close to zero at $h v_{\mathrm{exc}}=7.0-8.5 \mathrm{eV}$ and then drastically increases in the region of up to $h v_{\mathrm{exc}}=11 \mathrm{eV}$ (limit of measurements with discharge VUV sources). The intensity of the $118 \mathrm{~K}$ TSL peak in $\mathrm{Li}_{4} \mathrm{SiO}_{4}-2$ is about seven times lower than in $\mathrm{Li}_{4} \mathrm{SiO}_{4}-1$. An additional firing of $\mathrm{Li}_{4} \mathrm{SiO}_{4}-2$ in the argon atmosphere at $773 \mathrm{~K}$ for hydrogen release from the sample leads to the increase of the intensity of TSL and PSL in later irradiated sample by several times. It is not inconceivable that the investigation of $\mathrm{Li}_{4} \mathrm{SiO}_{4}-2$ type orthosilicates will be useful to the preliminary study of the processes of the release of deuterium and tritium from $\mathrm{Li}_{4} \mathrm{SiO}_{4}$ without any complicated experiments under neutron irradiation.

\section{Concluding remarks}

The emission spectra of various $\mathrm{Li}_{4} \mathrm{SiO}_{4}$ ceramics have been measured in the range of $1.8-5.8 \mathrm{eV}$ under irradiation by $6-30 \mathrm{eV}$ photons or $1-30 \mathrm{keV}$ electrons at $6-300 \mathrm{~K}$. The tunnel recombination phosphorescence, as well as luminescence, stimulated by $1.5-2.5 \mathrm{eV}$ photons has been detected in the sample preliminarily irradiated at 6 or $80 \mathrm{~K}$. The creation spectra of the $118 \mathrm{~K}$ TSL peak, as well as the excitation spectrum of PSL, span the region of the intrinsic absorption of a lithium orthosilicate $(9-30 \mathrm{eV})$. It is demonstrated that low-temperature, highly sensitive luminescent methods, based on the investigation of tunnel phosphorescence, TSL and PSL in lithium orthosilicates, have been very promising for the detailed investigation of $\mathrm{e}-\mathrm{h}$ processes with the participation of defects that serve as the traps for tritium (see, e.g. [2]) in high-temperature commercial fusion reactors.

In our opinion, a detail comparison of the obtained results with the data on further investigation of $\mathrm{Li}_{4} \mathrm{SiO}_{4}$ irradiated by high-energy particles, which cause defect creation by the knock-out (impact) mechanism, will allow us to separate the nonimpact (electron-hole) mechanisms of radiation damage. Of particular interest are the processes of defect creation in a cation sublattice of a lithium orthocilicate. Small-radius interstitial $\mathrm{Li}^{+}$(and possibly $\mathrm{Li}^{2+}$ ) ions can possess high mobility even at low-temperatures $(8-80 \mathrm{~K})$.

\section{Acknowledgements}

We are grateful to Prof. Ch. Lushchik for useful discussions, Dr. V. Babin and Dr. M. Kirm for assistance in the synchrotron experiments. This work has been supported by the Estonian Science Foundation (grant 6652) and the European Community - Research Infrastructure Action under the FP6 "Structuring the European Research Area" Programme (through the Integrated Infrastructure Initiative "Integrating Activity on Synchrotron and Free Electron Laser Science").

\section{References}

[1] G. Piazza, J. Reimann, E. Günther, R. Knitter, N. Roux, J.D. Lulewicz, J. Nucl. Mater. 307-311 (2002) 811.

[2] G. Piazza, F. Scaffidi-Argentina, H. Werle, J. Nucl. Mater. 283-287 (2000) 1396.

[3] K. Moritani, S. Tanaka, H. Moriyama, J. Nucl. Mater. 281 (2000) 106.

[4] S. Akahori, E. Tega, Y. Morimoto, K. Okuno, M. Nishikawa, K. Munakata, H. Moriyama, K. Kawamoto, M. Okada, J. Radioan. Nucl. Chem. 255 (2003) 257.

[5] A.D. Robertson, A.R. West, A.G. Ritchie, Solid State Ionics 104 (1997) 1.

[6] L. Skuja, M. Hirano, H. Hosono, K. Kajihara, Phys. Status Solidi C $2(2005) 15$.

[7] A.N. Trukhin, Nucl. Instr. and Meth. B 91 (1994) 334.

[8] Ch. Lushchik, V. Demidenko, M. Kirm, I. Kudryavtseva, A. Lushchik, I. Martinson, V. Nagirnyi, E. Vasil'chenko, J. Phys.: Condens. Matter 13 (2001) 6133. 
[9] K. Uchida, K. Noda, T. Tanifuji, Sh. Nasu, T. Kirihara, A. Kukuchi, Phys. Status Solidi A 58 (1980) 557.

[10] K. Noda, K. Uchida, T. Tanifuji, S. Nasu, Phys. Rev. B 24 (1981) 3736.

[11] M. Itoh, J. Murakami, Y. Ishii, Phys. Status Solidi B 213 (1999) 243.

[12] S. Tanaka, M. Taniguchi, H. Tanigawa, J. Nucl. Mater. 283-287 (2000) 1405.

[13] E. Vasil'chenko, I. Kudryavtseva, A. Lushchik, Ch. Lushchik, V. Nagirnyi, Phys. Status Solidi C 2 (2005) 405.

[14] S. Nakonechnyi, T. Kärner, A. Lushchik, Ch. Lushchik, V. Babin, E. Feldbach, I. Kudryavtseva, P. Liblik, L. Pung, E. Vasil'chenko, J. Phys.: Condens. Matter 18 (2006) 379.

[15] A. Lushchik, I. Kudryavtseva, Ch. Lushchik, E. Vasil'chenko, M. Kirm, I. Martinson, Phys. Rev. B 52 (1995) 10069.
[16] A. Lushchik, M. Kirm, I. Kudryavtseva, Ch. Lushchik, I. Martinson, V. Nagirnyi, E. Vasil'chenko, Radiat. Eff. Def. Solids 157 (2002) 537.

[17] A. Kotlov, S. Dolgov, E. Feldbach, L. Jönsson, M. Kirm, A. Lushchik, V. Nagirnyi, G. Svensson, B.I. Zadneprovski, Phys. Status Solidi C 2 (2005) 61.

[18] G. Zimmerer, Nucl. Instr. and Meth. A 308 (1991) 178.

[19] A. Trukhin, M. Kink, Y. Maksimov, R. Kink, Solid State Commun. 127 (2003) 655.

[20] M. Cannas, S. Agnello, F.M. Gelardi, R. Boscaino, A.N. Trukhin, P. Liblik, C. Lushchik, M.F. Kink, Y. Maksimov, R.A. Kink, J. Phys.: Condens. Matter 16 (2004) 7931.

[21] M. Kirm, G. Zimmerer, E. Feldbach, A. Lushchik, Ch. Lushchik, F. Savikhin, Phys. Rev. B 60 (1999) 502.

[22] A. Lushchik, M. Kirm, Ch. Lushchik, I. Martinson, V. Nagirnyi, E. Vasil'chenko, F. Savikhin, Nucl. Instr. and Meth. A 537 (2005) 45. 